\title{
Numerical Modelling of Composite Floor Slabs Subject to Large Deflections
}

\author{
M.M. Florides, K.A. Cashell * \\ Department of Mechanical, Aerospace and Civil Engineering, Brunel University, London, UK
}

\section{A R T I C L E I N F O}

\section{Article history:}

Received 14 June 2016

Received in revised form 21 September 2016

Accepted 17 October 2016

Available online xxxx

\section{Keywords:}

Composite slabs

Fire

Numerical modelling

Tensile membrane action

BRE method

\begin{abstract}
A B S T R A C T
This paper is concerned with the ultimate behaviour of composite floor slabs. Steel/concrete composite structures are increasingly common in the UK and worldwide, particularly for multi-storey construction. The popularity of this construction form is mainly due to the excellent efficiency offered in terms of structural behaviour, construction time and material usage all of which are particularly attractive given the ever-increasing demands for improved sustainability in construction. In this context, the engineering research community has focused considerable effort in recent years towards understanding the response of composite structures during extreme events, such as fires. In particular, the contribution made by the floor slab system is of crucial importance as its ability to undergo secondary load-carrying mechanisms (e.g. membrane action) once conventional strength limits have been reached may prevent overall collapse of the structure. Researchers have focused on developing the fundamental understanding of the complex behaviour of floor slabs and also improving the methods of analysis. Building on this work, the current paper describes the development and validation of a finite element model which can simulate the response of floor slab systems until failure, both at ambient and elevated temperature. The model can represent the complexities of the behaviour including the temperature-dependent material and geometric nonlinearities. It is first developed at ambient temperature and validated using a series of experiments on isolated slab elements. The most salient parameters are identified and studied. Thereafter, the model is extended to include the effects of elevated temperature so it can be employed to investigate the behaviour under these conditions. Comparisons with current design procedures are assessed and discussed.

(c) 2016 The Authors. Published by Elsevier Ltd on behalf of Institution of Structural Engineers. This is an open access article under the CC BY-NC-ND license (http://creativecommons.org/licenses/by-nc-nd/4.0/).
\end{abstract}

\section{Introduction}

Over the last number of years, the performance of buildings with steel/concrete composite floors during fire conditions has received increasing attention from the structural engineering community (e.g. [1-3]). This mainly followed observations during real building fires such as the Broadgate and Basingstoke fires where buildings with composite floors performed much better than expected due to the ability of the slabs to survive and redistribute loads around the structure. Largescale experiments were conducted at Cardington [4] to investigate the behaviour under more controlled conditions and it was observed that traditional prescriptive design methods are overly conservative and steel-framed buildings with composite floors inherently possess sufficient ductility and resistance during extreme events to delay or even prevent failure. The Cardington experiments led to a surge in interest from the engineering research community with work focused on developing a greater understanding of the behaviour through further experimental and numerical analysis.

\footnotetext{
* Corresponding author.

E-mail addresses: Marios.Florides@brunel.ac.uk (M.M. Florides), Katherine.Cashell@brunel.ac.uk (K.A. Cashell).
}

The response of a two-way spanning floor slab during a fire is particularly complex owing to the interrelated material and geometric nonlinearities which develop with increasing levels of deflection and temperature. Although the slab exhibits significantly lower bending capacity in a fire due to the degradation of material strength and stiffness, the development of tensile membrane action can lead to a greater overall capacity than predicted by the design codes (e.g. Eurocodes). However, before tensile membrane action can be incorporated into design standards, a detailed and fundamental understanding of the behaviour of floor slab must be attained.

Towards this end, a limited number of experimental programmes have studied the large-deflection performance of isolated slab elements both at ambient and elevated temperature (e.g. [2,5]). However, largescale experiments are prohibitively expensive and time-consuming and so a full examination of the various parameters affecting the behaviour is not realistically feasible. Therefore, a number of purpose built numerical models have been developed by the research community to study the effects influencing the response of structures and floor slabs in particular under fire loading scenarios (e.g. [6,7]). Although these models have led to considerable advancement in the understanding of structures in fire, they are often not suitable for design as they can be computationally expensive and the scale of the structures may be difficult to realistically represent. Practical design guidance and software for 
steel framed buildings with composite floor slabs in fire have been proposed, the most well-known of which is the BRE method [8,9], to help engineers achieve safe and efficient designs. However, several shortcomings of the BRE method have been presented by various researchers (e.g. 3, [10]) including an absence of appropriate failure criteria and also a lack of consistency in terms of the method providing a conservative or unconservative assessment of the load carrying capacity, depending on the aspect and reinforcement ratios of the slab.

The main focus in this paper is the development of a numerical model that can accurately predict the response of isolated simplysupported strip and slab elements in both ambient and elevated temperature conditions until failure. This work is part of a larger research programme which will investigate the effects of various boundary and geometric properties and also propose analytical solutions. Importantly, the model considers the highly influential effect of bond strength between the steel reinforcement and surrounding concrete on the ultimate performance; this has already been shown to be critical for assessing the level of load and deflection which can be sustained before failure $[2,3]$. Accordingly, this paper proceeds with an overview of recent studies carried out to examine the ultimate performance of oneand two-way spanning lightly reinforced elements, such as composite floor slabs. A finite element model is developed using the ABAQUS software; the model is first described for ambient conditions and validated against a series of experiments on isolated members. Subsequently, the results are compared with those obtained utilising the finite element software VULCAN and the BRE method. This is an essential precursor to further expansion of the model to incorporate the effects of elevated temperature, such as those which occur during a fire.

\section{Development of the numerical model}

A finite element model (FEM) has been developed using the commercially-available ABAQUS software [11] which is capable of achieving numerical convergence despite the geometric and material nonlinearities of the behaviour. Many different finite element packages can be used for this purpose and have been by other researchers (e.g. [3, $7,12]$ ). However, ABAQUS was selected for this work because great importance is given to being able to readily compare results to those from other researchers and, more importantly, developing models and procedures which are not reliant on proprietary software.

In order for the FEM to accurately predict the response of slabs with various combinations of material and geometrical properties and to ensure that the model is readily usable by designers, a number of steps were followed in the modelling procedure. During this process, importance was given to ensuring that the material and geometric properties such as concrete/reinforcing steel strength, dimensions and boundary conditions were realistically represented and yet ensuring that the model requires knowledge only of the typical properties which are known by designers. Owing to the complexity of the behaviour of two-way spanning slabs, the model was developed in three major steps: (i) one-way spanning slab strips at ambient temperature (ii) two-way spanning slabs at ambient temperature and (iii) incorporation of the effects of elevated temperature. The first two stages are very important and an essential pre-requisite for understanding the mechanical behaviour of these elements at large deflections, such as those that occur in a fire. In the following sections, the development of the oneand two-way spanning models is first described, including the material representations. The inclusion of elevated temperature effects is discussed later in Section 4.

\subsection{One-way spanning slab strips}

The task of creating a FEM that is user-friendly on the one hand and also able to reliably simulate the behaviour of reinforced concrete elements on the other is extremely challenging. This is mainly due to the nature of the material behaviour, particularly the interaction between the reinforcing steel and the surrounding concrete, a subject that has been the focus of many researchers (i.e. [13,14]). In the current research programme, a great deal of importance was given to the representation of bond between the steel and the concrete in the model and, in particular, ensuring that it was included in a manner which is appropriate for designers. This means using methods which only require the typical material and geometric properties which are known by engineers (e.g. material strength, stiffness, dimensions, etc.). For this reason, and since the analysis of slab elements can be based on strip element analysis (particularly of one-way spanning slab members), the FEM described hereafter was calibrated and validated using a recent series of ambient temperature tests on isolated slab strips with various geometric and material properties, including bond strength. For brevity, only a brief account of the tests is given herein with a more comprehensive description available elsewhere [14].

Fig. 1 shows the general geometry of the specimens and the testing rig, whilst more specific details of each specimen are described in Table 1 which gives the half-length $(L)$, width $(b)$ and depth $(h)$ of the strips, as well as the reinforcement ratio $(\rho)$, concrete compressive strength $\left(f_{c}\right)$ and concrete tensile strength $\left(f_{t}\right)$. The effective depth of the reinforcement from the compressive face is half the overall depth (i.e. $h / 2$ ) in all cases. Four types of reinforcement were considered in the test programme, namely: (i) plain bars with a diameter of $6 \mathrm{~mm}$ (P6); (ii) deformed bars with a diameter of $6 \mathrm{~mm}$ (D6); (iii) deformed bars of $8 \mathrm{~mm}$ diameter (D8); and (iv) A142 welded mesh consisting of $6 \mathrm{~mm}$ deformed bars spaced at $200 \mathrm{~mm}$ centres (M6).

In the ABAQUS FEM, the concrete elements were modelled using 3D solid elements with reduced integration from the ABAQUS library (C3D8R). The model employed a square mesh comprising of $20 \mathrm{~mm}$ cubic elements, based on a mesh sensitivity assessment. Solid elements were employed because although computationally expensive, they better represent damage in the material and the relationship between the concrete and the embedded reinforcement at elevated temperature, which is particularly important in this study. The reinforcement was modelled using linear 3D truss elements (T3D2) which were embedded in the solid concrete elements. Due to symmetry, only a part of the specimens was modelled such that one reinforcement bar was included in the concrete at any time (Fig. 2). The strips rest on a fixed rigid frame and are free to move both rotationally and laterally. The loading arrangement was identical to that in the testing procedure which is shown in Fig. 1 and the elements were loaded in displacementcontrol. Although ABAQUS includes several static analysis methods, in order to facilitate both the ambient and elevated-temperature loading, a quasi-static dynamic, implicit analysis was employed in this study.

\subsection{Two-way spanning slabs}

The one-way spanning strip model described in the previous section was extended for two-way spanning slabs. The steel decking was not included in the analysis because it was observed during real fire tests that it de-bonded from the concrete slab at an early stage and ceased to contribute to the load-carrying capacity of the slab [8]. Similarly to the oneway spanning elements, the concrete slab panels were modelled using

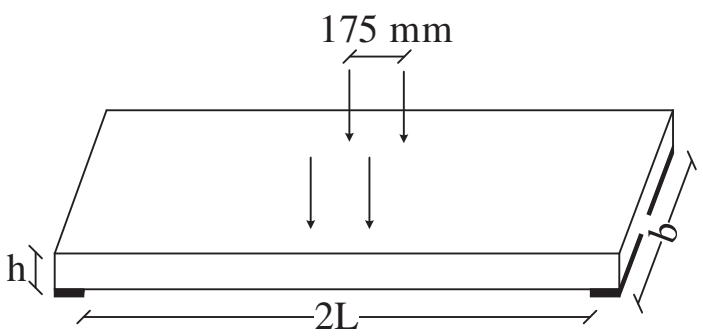

Fig. 1. General schematic of strip tests and test rig [14]. 
Table 1

Properties of the strip tests [14].

\begin{tabular}{llllllll}
\hline Model & $\mathrm{L}(\mathrm{mm})$ & $\mathrm{b}(\mathrm{mm})$ & $\mathrm{h}(\mathrm{mm})$ & Bar type & $\rho(\%)$ & $\mathrm{f}_{\mathrm{c}}\left(\mathrm{N} / \mathrm{mm}^{2}\right)$ & $\mathrm{f}_{\mathrm{ct}}\left(\mathrm{N} / \mathrm{mm}^{2}\right)$ \\
\hline UR1 & 500 & 600 & 60 & M6 & 0.24 & 29.9 & 2.2 \\
UR2 & 500 & 600 & 60 & M6 & 0.24 & 29.9 & 2.2 \\
UR3 & 500 & 600 & 60 & P6 & 0.24 & 29.9 & 2.2 \\
UR4 & 700 & 600 & 60 & D6 & 0.24 & 31.9 & 2.1 \\
UR5 & 700 & 600 & 40 & D6 & 0.35 & 31.9 & 2.1 \\
UR6 & 700 & 600 & 60 & P6 & 0.24 & 47.7 & 3.1 \\
UR7 & 700 & 540 & 60 & P6 & 0.52 & 47.7 & 3.1 \\
UR8 & 700 & 540 & 60 & D6 & 0.52 & 47.7 & 3.1 \\
UR9 & 700 & 480 & 60 & D8 & 0.52 & 47.7 & 3.1 \\
UR10 & 700 & 600 & 60 & M6 & 0.24 & 40.4 & 2.4 \\
UR11 & 700 & 500 & 60 & D8 & 0.35 & 40.4 & 2.4 \\
UR12 & 700 & 450 & 90 & D8 & 1.2 & 40.4 & 2.4 \\
UR13 $^{7} 700$ & 600 & 60 & D6 & 0.24 & 40.4 & 2.4 \\
UR14 $^{\mathrm{a}}$ & 700 & 480 & 60 & D8 & 0.52 & 31.9 & 2.5 \\
UR15 $^{\mathrm{a}}$ & 700 & 480 & 90 & $\mathrm{D} 8$ & 0.35 & 31.9 & 2.5 \\
UR16 $^{\mathrm{a}}$ & 700 & 480 & 120 & $\mathrm{D} 8$ & 0.26 & 31.9 & 2.5 \\
\hline
\end{tabular}

a Special strip incorporating internally instrumented bars.

3D solid elements with reduced integration (C3D8R) from the ABAQUS library and the reinforcement using linear 3D truss elements (T3D2) which were embedded in the solid slab elements. Due to symmetry, only a quarter of the slab was modelled (Fig. 3). The slab was simply supported and free to move both rotationally and laterally at the supports (the slab rests on a fixed rigid frame that restrains only the vertical movement of the slab whilst rigid anchors prevent the reinforcement to slip through the concrete once pulled by any resulting deflections of the slab). The loading arrangement can be varied (e.g. uniformly distributed, point loads, etc.) and the slabs were loaded in displacement-control.

\subsection{Ambient temperature material properties}

\subsubsection{Concrete}

The concrete was modelled using the concrete damaged plasticity (CDP) model in ABAQUS. There are a number of different constitutive models available in the ABAQUS software and the CDP model was selected for this analysis because it facilitates all aspects of the work including the effects of varying temperature and loading conditions on the response. In the CDP model, the concrete is represented using the concept of isotropic damaged elasticity in combination with isotropic tensile and compressive plasticity to represent the inelastic behaviour of concrete, and a combination of multi-hardening plasticity and isotropic damaged elasticity to describe the irreversible damage that occurs during the fracturing process. Accordingly, the material behaviour is defined in terms of the elastic, plastic, compressive and tensile properties.

The elastic properties were represented in accordance with CEB-FIP Model Code 90 [15]. The Poisson's ratio and density of concrete were taken as 0.2 and $2400 \mathrm{~kg} / \mathrm{m}^{2}$, respectively. In addition to the compressive and tensile constitutive relationships, a number of other parameters are required in the CDP model, including: (i) dilation angle; (ii) eccentricity; (iii) ratio of the strength in the biaxial state to the strength in the uniaxial state $\left(\mathrm{f}_{\mathrm{bo}} / \mathrm{f}_{\mathrm{co}}\right)$; (iv) parameter $\mathrm{K}$; and ( $\mathrm{v}$ ) viscosity parameter. The dilation angle was assigned a value of $38^{\circ}$, within the common

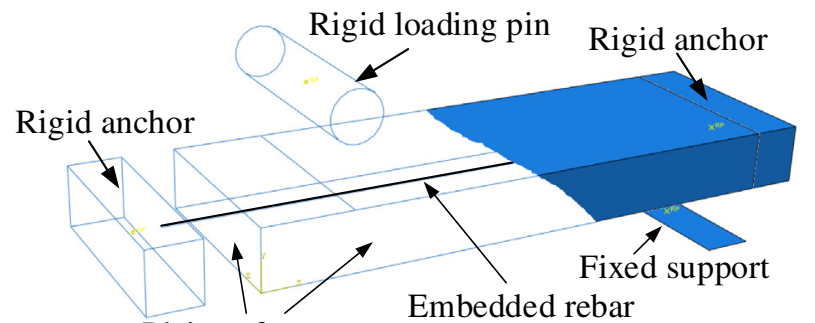

Plains of symmetry

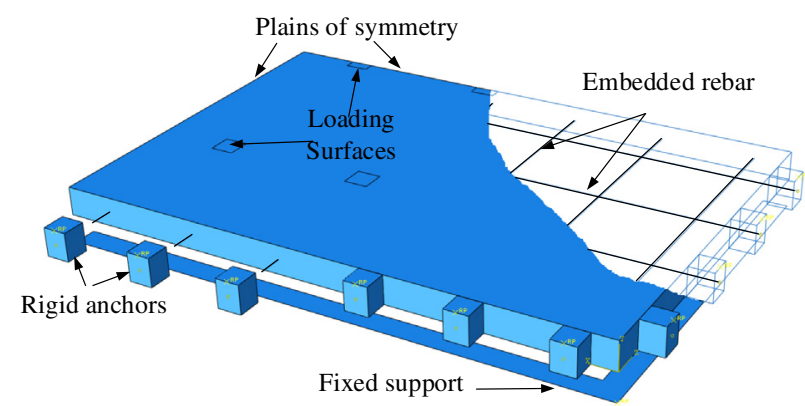

Fig. 3. Two-way model arrangement.

range used by other researchers [16], whilst the other parameters were assigned the default ABAQUS values. More detailed discussion on the simulation of concrete in both compression and tension is presented in the following sub-sections.

2.3.1.1. Compressive behaviour. The uniaxial compressive response of concrete was represented in the model using the CEB-FIP Model Code 90 [15] as shown in Fig. 4. In this model, the material behaves in a linear elastic manner up to an initial yield stress equal to 0.4 times the concrete strength $\left(0.4 f_{c}\right)$. Thereafter, the behaviour becomes inelastic with some hardening initially until the maximum compressive stress $\left(f_{c}\right)$ is reached before softening behaviour occurs beyond the peak stress. In the analysis, the average compressive strength of the concrete measured during the experimental programme (which is discussed in Section 2.1 and presented in Table 1 ) is incorporated into the model.

2.3.1.2. Tensile behaviour. There are a number of different approaches employed by researchers to represent the tensile behaviour of concrete (e.g. $[13,15,18-20])$. In this analysis, the Wang and Hsu [21] approach was employed because it has been well established and validated over a period of years using a number of similar structural arrangements to the current work. The model is shown in Fig. 5 and defined by Eqs. (1) and (2):

$f=E_{c} \varepsilon \quad \varepsilon \leq \varepsilon_{c r}$

$f=f_{c t}\left(\frac{\varepsilon_{c r}}{\varepsilon}\right)^{0.4} \quad \varepsilon>\varepsilon_{c r}$

where $f$ is the concrete stress, $E_{c}$ is the modulus of elasticity of concrete, $f_{c t}$ is the cracking stress of concrete and $\varepsilon_{c r}$ is the cracking strain.

As shown in Fig. 5, the model assumes that the tensile stress increases linearly with tensile strain until the concrete cracking stress $\left(f_{c t}\right)$ and strain $\left(\varepsilon_{c r}\right)$ is reached, as given in Eq. (1). Once cracking occurs, the tensile stress decays as the concrete softens, in accordance with

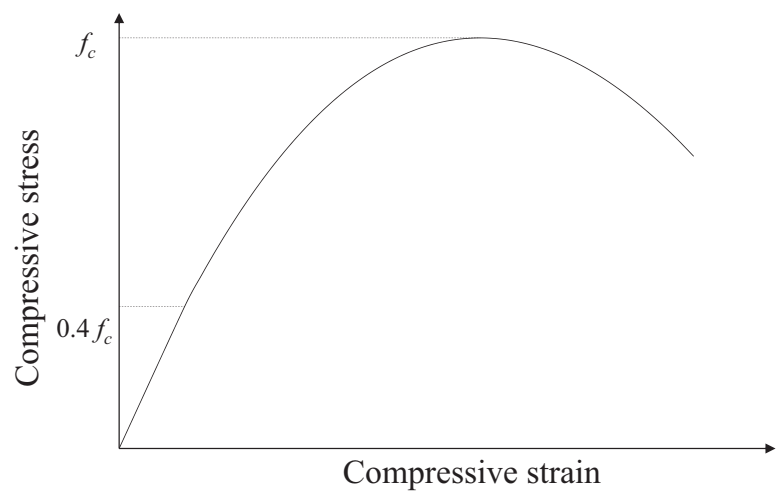

Fig. 4. Response of concrete to uniaxial loading in compression. 


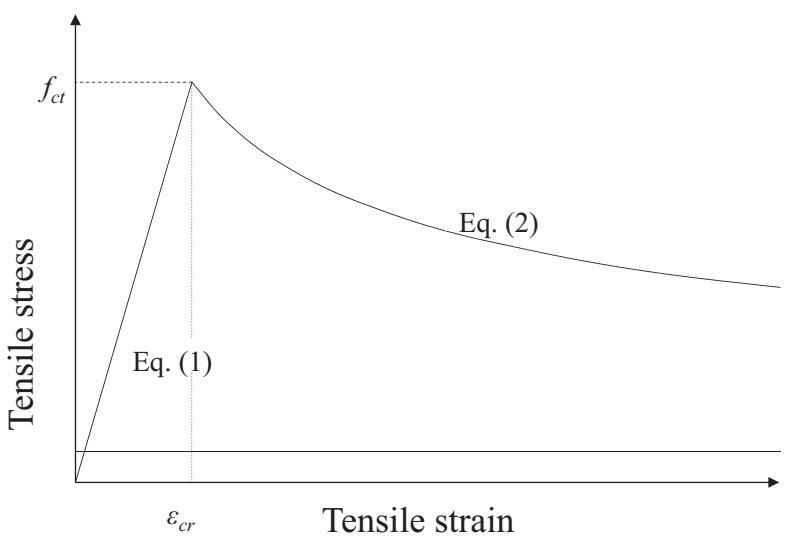

Fig. 5. Response of concrete to uniaxial loading in tension.

Eq. (2). The post-peak stress-strain softening behaviour of concrete is modelled in ABAQUS using the "tension stiffening" property, which allows the user to define the strain-softening response of the cracked concrete. The rate of softening, which depends on the exponent in Eq. (2) denoted as the reduction factor (RF) hereafter, is very influential to the ultimate performance of the concrete member as it represents the contribution made by the concrete in tension to the overall response, post-cracking. In effect, this tension stiffening property inherently accounts for the bond strength between the steel and the concrete. Any adjustment of the RF in Eq. (2) is effectively changing the bond relationship between the steel and the concrete and hence the contribution made by the concrete in tension to the overall response after cracking has occurred. This directly affects the distribution of strain in the reinforcing steel across any crack opening, which is critical at failure. The effect of the RF employed on the response of the model is discussed in detail later in Section 3.3.1.

\subsubsection{Steel reinforcement material properties}

The uniaxial tensile response of reinforcing steel was represented in the model using the bilinear relationship presented in Eurocode 2 Part 1-1 [22] which is reproduced in Fig. 6. In this model, the material is linear up to the yield stress $\left(f_{y}\right)$. Thereafter, the behaviour becomes inelastic with hardening until the ultimate stress $\left(f_{u}\right)$ is reached. In the analysis, the corresponding strain values at $f_{y}$ and $f_{u}$ are taken from the experimental programme described before.

\subsection{Elevated temperature material properties}

In order to evaluate the response of the models in elevated temperature the material properties had to be modified in order to consider the degradation effects of high temperature. Additionally to the degradation

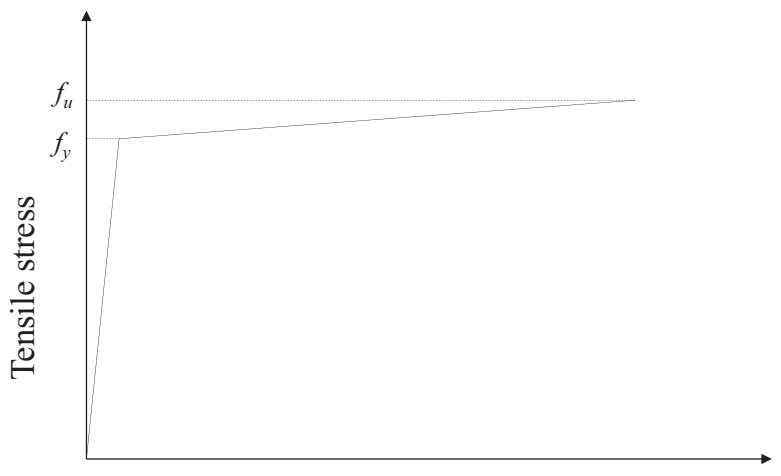

Tensile strain of the material strength, other parameters had to be set up in ABAQUS in order to establish a realistic scenario of temperature distribution along the depth of the concrete (and the embedded reinforcement) as well as the developed stresses resulting from thermal expansion. These parameters are thermal conductivity, thermal expansion and specific heat. The values of these variables as set in the numerical model are provided in this section by Figs. 7-11 (based on EN 1992-1-2 [17]) but discussed later in Section 4.

\section{Ambient temperature response}

\subsection{Validation of the numerical model at ambient temperature: one-way elements}

This section focuses on comparing and discussing the FEM response with the results from the tests presented in Table. The majority of these tests failed by fracture of the reinforcement across a central failure crack, unless otherwise stated hereafter. Figs. 11-15 illustrate the load-deflection response of all specimens containing M6, P6, D6, D8 and the instrumented D8 bars, respectively. In this analysis, the reduction factor RF used to calculate the values for the tension stiffening in ABAQUS was selected as 0.7 (dimensionless). In terms of the loaddeflection response, it can be seen that the FEM provides a good representation of the behaviour in all cases, including the prediction of ultimate load. Fig. 16 depicts the crack patterns which were observed in the experiments, together with the crack patterns predicted by the FEM which are also in good agreement.

With reference to the load-displacement responses for M6 bars in Fig. 11, it is evident that although UR1 and UR2 had identical geometric and material properties, their experimental responses showed considerable differences at large levels of displacement. This is attributed mainly to the significant influence of bond strength on the overall behaviour and the fact that this property is influenced by numerous factors (e.g. casting, concrete mix, compacting, aggregate interlocking etc.). In this context, the FEM response is reasonable compared with the experimental graph.

Although plain round steel is no longer included in the Eurocodes and is rarely specified in new buildings, it is still very relevant for existing structures. The tests containing P6 bars were modelled and the results are presented in Fig. 12. Due to the high ductility of this reinforcement, as well as the relatively low bond strength achieved by plain bars, it is unsurprising that these specimens failed at significantly higher displacements compared with the specimens with ribbed reinforcement. Moreover, it is noteworthy that these specimens tended to develop only a single crack in the centre, as shown in Fig. 16(a). As with the M6 specimens, the FEM is shown to provide a satisfactory simulation of the load-deflection behaviour, with deviations at higher displacements attributed to the very low bond strength in these members.

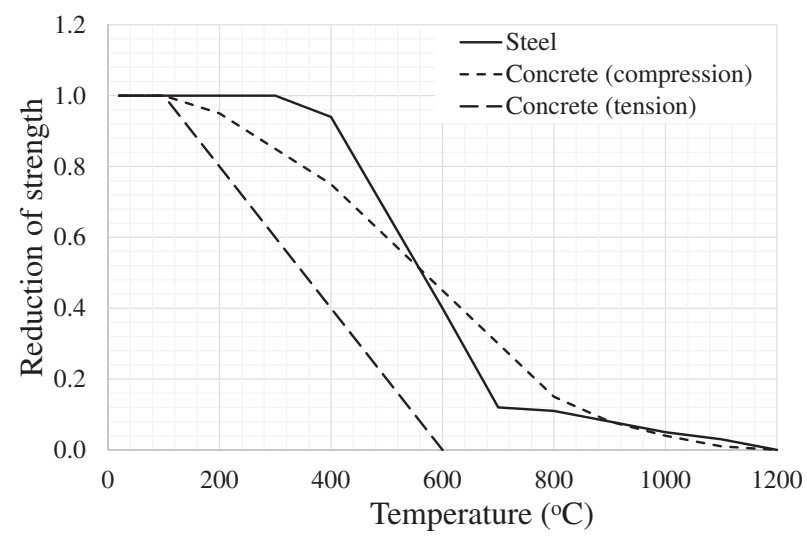

Fig. 7. Reduction rate of material strength with increasing temperature 


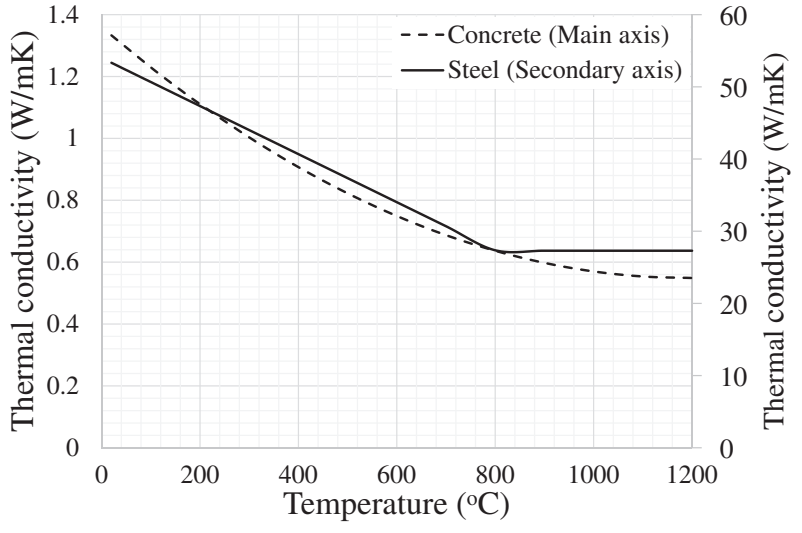

Fig. 8. Thermal conductivity of steel and concrete with increasing temperature.

The specimens containing D6 reinforcement are presented in Fig. 13(a) and (b). The first of these graphs presents the load-deflection response for tests UR5 and UR8 in which several cracks developed at low levels of deflection. Both the experimental and FEM crack pattern are shown in Fig. 16(d) where it can be clearly seen that the FEM depicts the crack formation well. There is a considerable deviation between the experimental and numerical responses for specimen UR8 as the level of deflection increases; this is attributed to the high strength of concrete $\left(f_{c}=47.7 \mathrm{~N} / \mathrm{mm}^{2}\right)$ in comparison to the other specimens (i.e. for UR1 and UR2, $f_{c}=29.9 \mathrm{~N} / \mathrm{mm}^{2}$ ). Fig. 13(b) presents the loaddeflection responses for tests UR4 and UR13 where only two additional cracks (Fig. 16(c)) to the main failure crack formed. Similarly to UR8, the higher concrete strength affects the results of UR13, although the numerical model generally represents the behaviour reasonably well.

The load-deflection responses for the specimens containing D8 reinforcement (i.e. UR9, UR11 and UR12) are presented in Fig. 14. These specimens behaved differently to those previously discussed in that they failed by concrete crushing rather than fracture of the reinforcement. There is a detailed discussion on the different failure modes elsewhere [14], but of interest in the current study is that the FEM response indicates similar cracking characteristics. With reference to Fig. 16(e), longitudinal cracking developed in the region close to the primary failure crack, in the same location as where the reinforcement was placed. In the load-deflection response predicted by the FEM (i.e. UR12 in Fig. 14), this phenomenon is distinguished by the stepped load pattern immediately after maximum load capacity is reached. The selection of a bilinear material constitutive relationship for the reinforcing steel without any softening branch (as included in EN 1992-1-1) means that the softening in the load-deflection response obtained by the FEM is due to concrete crushing.

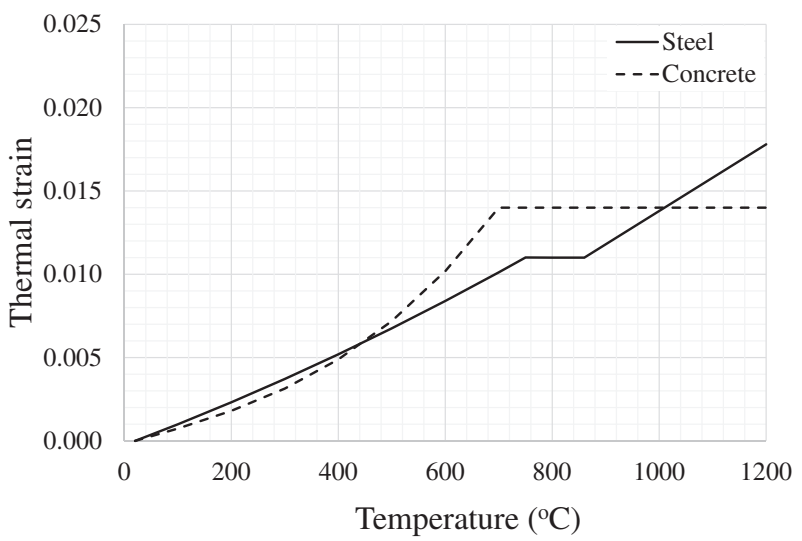

Fig. 9. Thermal elongation of steel and concrete with increasing temperature.

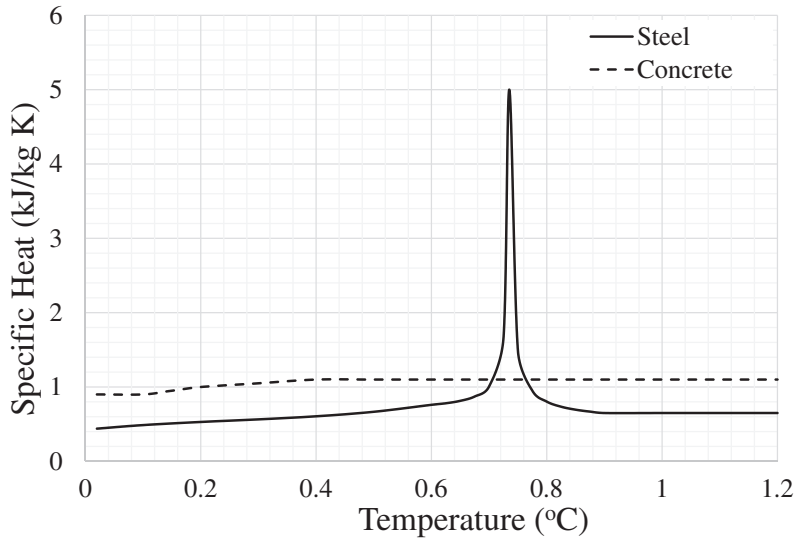

Fig. 10. Specific heat of Steel and concrete with increasing temperature.

The results from tests UR14, UR15 and UR16 are presented in Fig. 15. Their representation by the FEM is in good agreement with the experimental behaviour. Each of the three specimens developed different number of cracks due to the different reinforcement ratios with multiple cracks ( $>8$ ) forming in UR14, five in UR15 and just three for UR16. The model was able to predict both the number and the location of the cracks for all models as shown in Fig. 16(d). These three specimens will be discussed in more detail later as they were instrumented with strain gauges in the reinforcement, enabling a closer analysis of the bond distribution. It is evident from the above discussion and the results presented that the material models used in the FEM were effectively calibrated so that the tests were well represented and the model is capable of predicting the response of one-way lightly reinforced concrete elements until failure with reasonable accuracy (the failure prediction is discussed in more detail in Section 3.3.2).

\subsection{Validation of the numerical model at ambient temperature: two-way elements}

In this section, the FEM for the two-way spanning slab elements described previously is validated using a series of ambient temperature tests on isolated slab members with various geometric and material properties. The tests focused on lightly reinforced concrete slab specimens with the main aim of providing a greater insight into the large displacement behaviour of composite floor slab systems. For brevity, only a brief account of the tests will be given herein with a more comprehensive description available elsewhere [2]. Fig. 17 shows the general geometry of the two different types of specimens tested (the slabs had an aspect ratio of either 1 or 1.5), whilst Table 2 provides the relevant geometric and material properties for all slab specimens. The reference

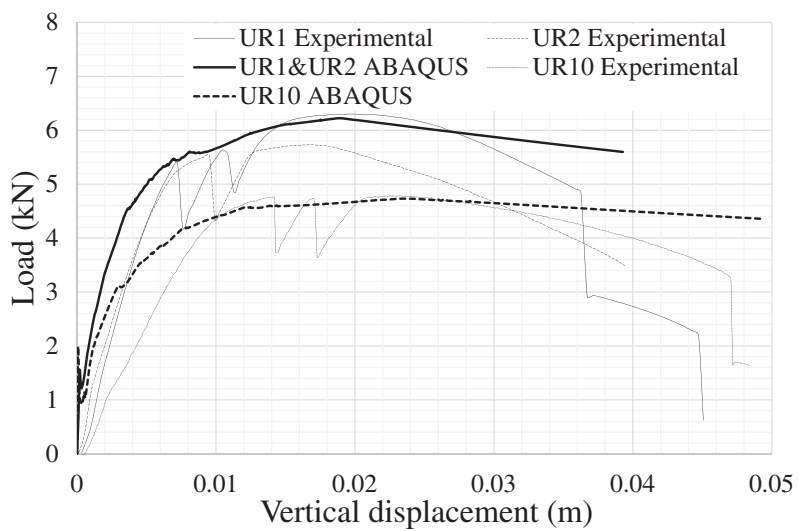

Fig. 11. Load-displacement response of members with M6 reinforcing bars. 


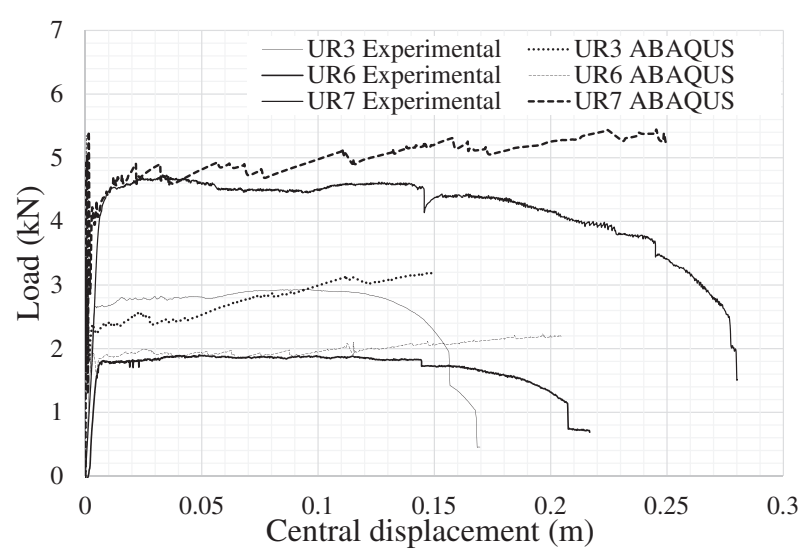

Fig. 12. Load-displacement response of members with P6 reinforcing bars.

system adopted in labelling each specimen is kept the same as in the original work and is as follows: the first parameter denotes a rectangu$\operatorname{lar}(\mathrm{R})$ or square $(\mathrm{S})$ slab; F40 and F60 represent the depth of the slab in $\mathrm{mm}$; the third parameter describes the reinforcement used (similarly to Table 1) whilst A, B, C and D signify various reinforcement arrangements used. The table also includes information relating to the depth of the slab $\mathrm{H}$, the long and short spans $L_{1}$ and $L_{2}$, respectively, and also $\rho_{1}$ and $\rho_{2}$, which are the reinforcement ratios in the long and short spans. All specimens have been modelled using the FEM and one typical experiment is selected herein (S-F60-M6-A) for a detailed analysis of the load-deflection and temperature-deflection performance (see Section 4).

(a)

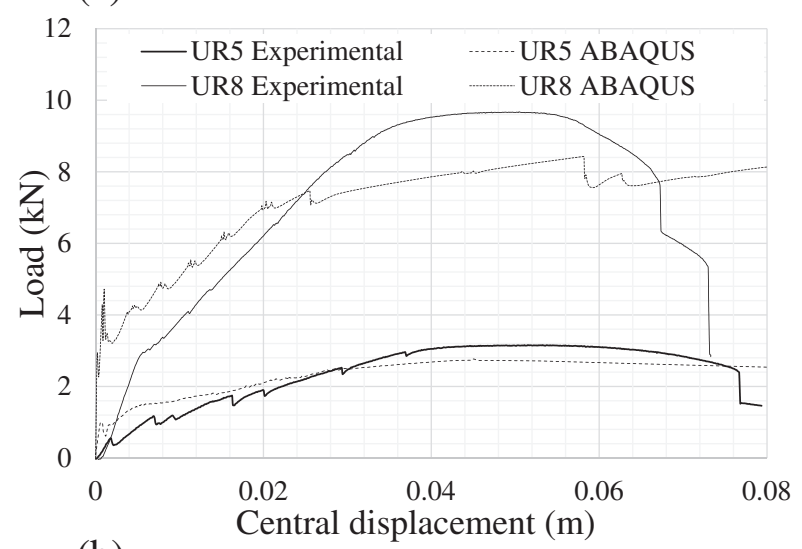

(b)

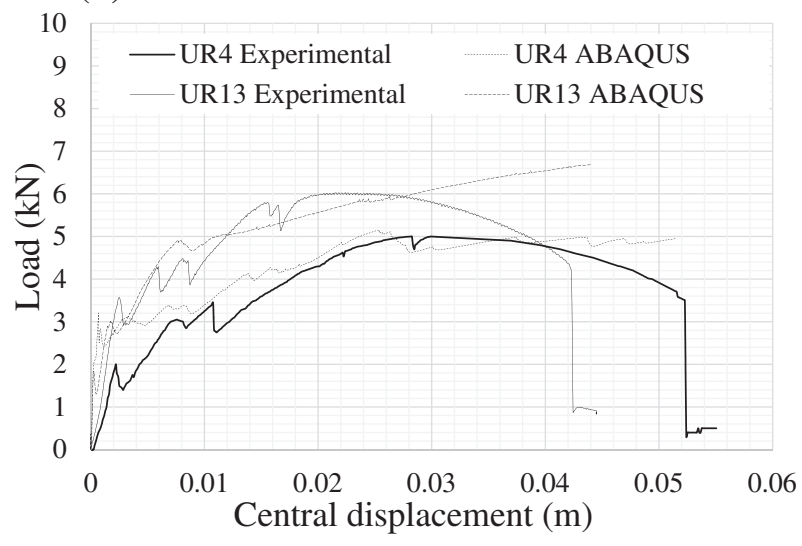

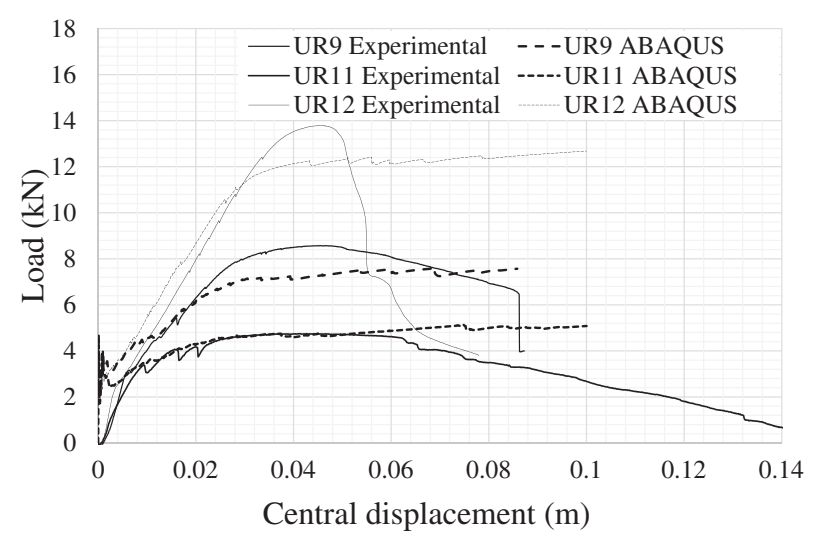

Fig. 14. Load-displacement response of members with D8 reinforcing bars.

Fig. 18(a) shows the crack pattern for specimen S-F60-M6-A whilst the FEM prediction for the same specimen is given in Fig. 18(b). Clearly, the model depicts the development of conventional yield line cracks as well as the additional cracks in the centre of the slab. The experimental and numerical load-deflection response for slab specimen S-F60-M6-A is given in Fig. 19. Also presented in the same graph are the results using the BRE analytical method $[8,9]$ as well as the prediction from another commonly-used finite element model, VULCAN [23]. The BRE simplified design method estimates the load-carrying capacity of a lightly reinforced concrete slab as a function of the vertical displacement based on the in-plane stresses (membrane action) in the slab. VULCAN, on the other hand, is a finite element package which was first developed at the University of Sheffield to model the 3dimensional nonlinear behaviour of composite steel-framed buildings under fire conditions. It has been extensively validated since its development and is used herein to ratify the results obtained from the ABAQUS FEM.

In the VULCAN model, a 9-noded quadrilateral plate element (as shown in Fig. 20) is used to model the slab specimens which can capture both the bending and membrane effects. Each element is divided into 16 layers of which 14 represent the concrete with the remainder used for the representation of the steel reinforcement. The configuration of the model is an exact replica of the experimental conditions at ambient temperature.

The load-deflection response shown in Fig. 19 for the specimen SF60-M6-A illustrates that the overall behaviour of the slabs is well described by the FEM. First cracking of the concrete, evidenced by the drop in load at small levels of deflection, is well predicted. Furthermore, yielding of the reinforcing steel is also well simulated with reasonable accuracy until failure.

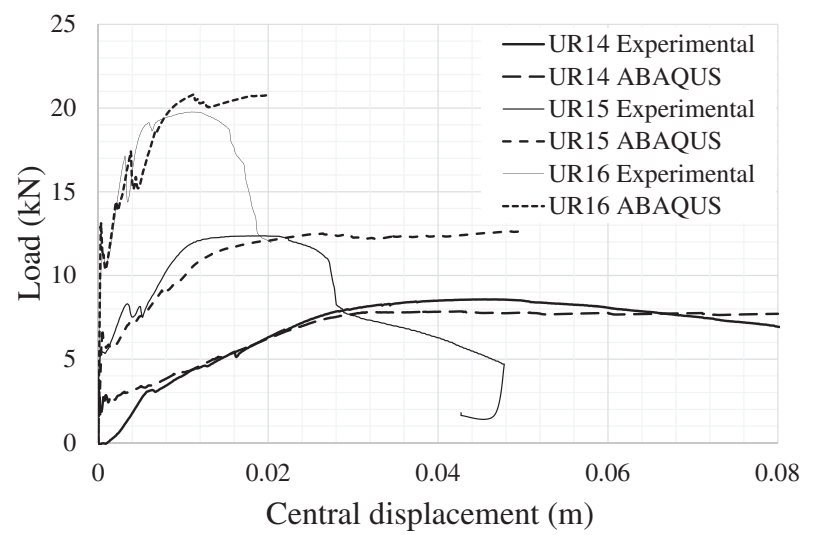

Fig. 13. (a) \& (b) Load-displacement response of members with D6 reinforcing bars.

Fig. 15. Load-displacement response of members with instrumented D8 reinforcing bars. 
(a)

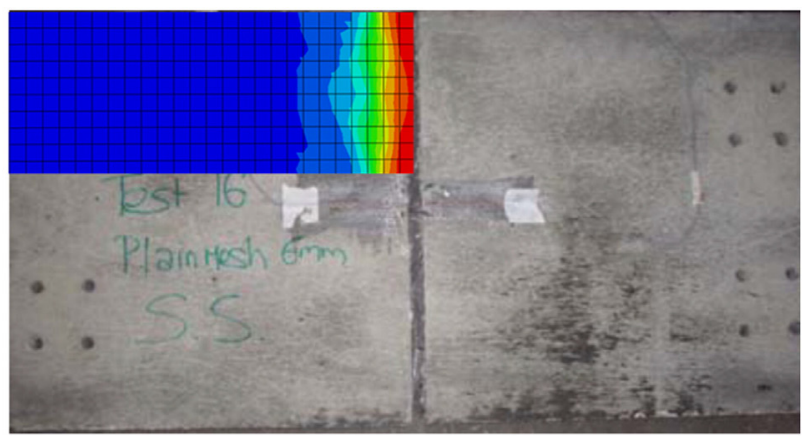

(b)

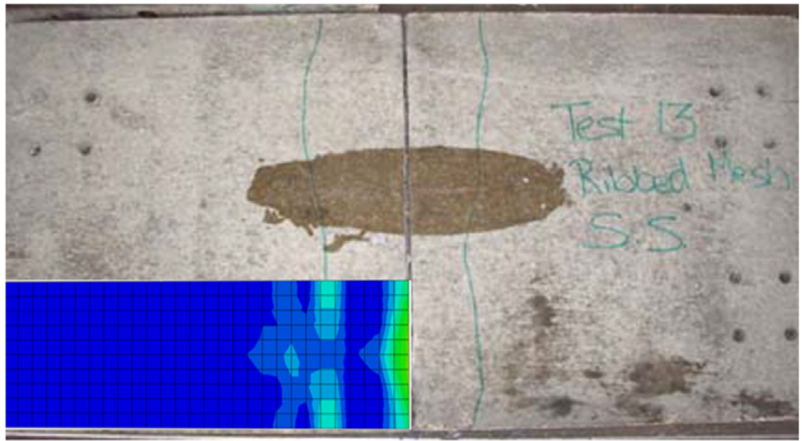

(c)

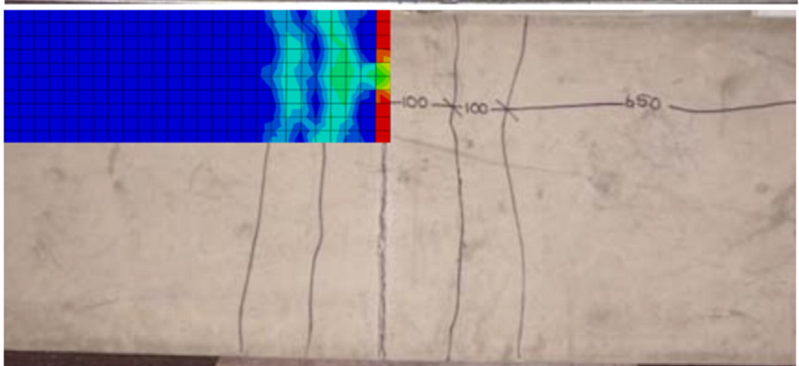

(d)

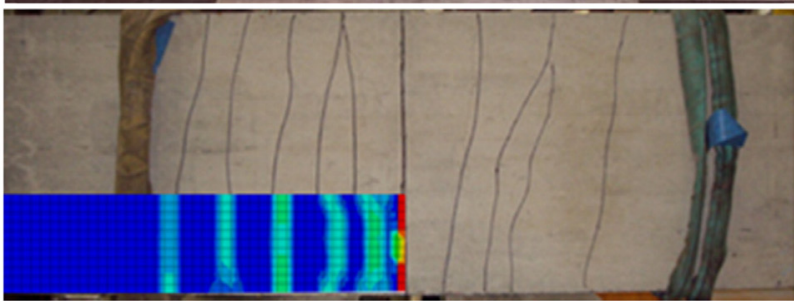

(e)

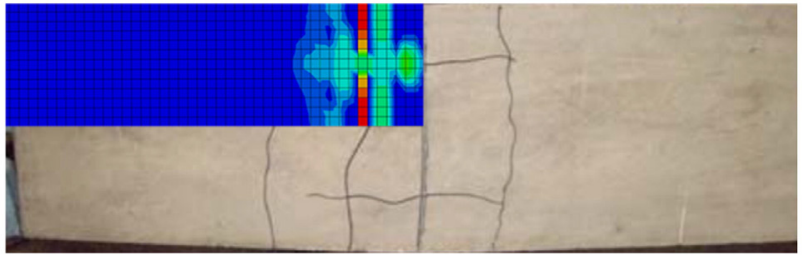

Fig. 16. Possible crack patterns: (a) single midspan crack as developed in UR3, UR6 and UR7, (b) multiple cracks $(<4)$ as developed in UR1, UR2, UR9, UR10 and UR16 (c) multiple cracks $(<6)$ as developed in UR4, UR13 and UR15, (d) multiple cracks ( $>8$ ) as developed in UR5, UR8, UR12 and UR14, and (e) cracking parallel to the reinforcement as developed in UR11.

The VULCAN model also provides a very good representation of the nonlinear behaviour of the slabs. Although only one slab is presented herein owing to brevity, the other slabs in this test programme have also been studied and show similarly good results. The BRE method provides a reasonable prediction of the response at small deflections in ambient temperatures but this prediction becomes less representative and overly conservative at large deflections.

In terms of failure, the slab failed by fracturing of the steel reinforcement across a localized through-depth crack across the shorter span. The ultimate strain of the steel reinforcement in the tests was found

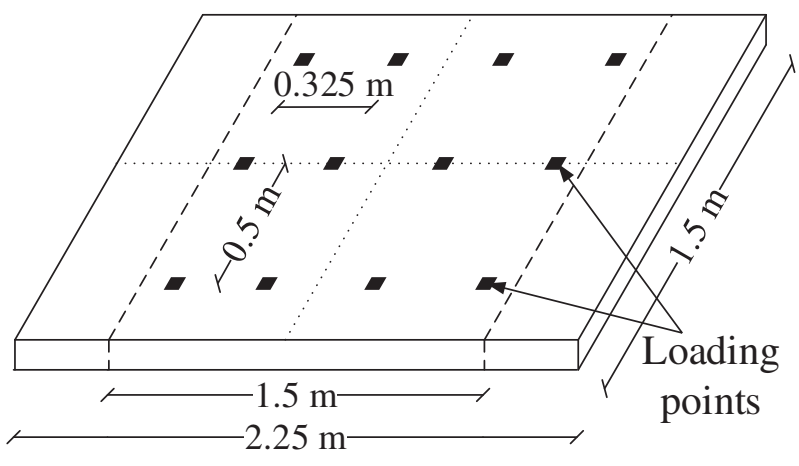

Fig. 17. Layout of the slab specimens.

through tensile testing to be $0.033 \%$, as indicated in the Fig. 19 . Also presented in the graph using the secondary y-axis is the FEM prediction for the strain induced in the reinforcement along the failure crack for the corresponding vertical displacement of the slab.

\subsection{Parametric study}

In this section, the numerical models previously described for oneand two-way spanning slab elements are used to investigate the key parameters which influence the response. As bond strength is so important in terms of the ultimate behaviour, both the concrete model selected and the representation of the bond relationship between the steel and the concrete are examined.

\subsubsection{Effect of concrete tension model on the numerical response}

As briefly discussed previously in Section 2.3.2, there are a number of different approaches for representing the tensile behaviour of concrete in numerical models; the Wang and Hsu method [21] was selected for the analysis presented earlier in this paper. As the tensile response is very important in terms of the failure behaviour of lightly reinforced concrete specimens, this section investigates the effect that tension stiffening has on the behaviour by comparing the Wang and Hsu model with the tensile model presented in the CEB-FIP Model Code 90 [15]. The CEB-FIP approach states that since tensile failure of concrete is always a discrete phenomenon, its tensile behaviour is best described using a stress-strain diagram for uncracked concrete and a stresscrack opening diagram for the cracked section. On the other hand, the most common way to model cracking in a finite element model of a reinforced concrete specimen is to assume that the cracks are distributed over the area of the finite element using the smeared cracking approach and to include this in the calculations by changing the stress and the material stiffness associated with the affected elements and nodes during the analysis. The CDP model in ABAQUS incorporates a smeared

Table 2

Properties of the slab tests [2]

\begin{tabular}{lllllll}
\hline Model & $\mathrm{L}_{1}(\mathrm{~mm})$ & $\mathrm{L}_{2}(\mathrm{~mm})$ & $\mathrm{h}(\mathrm{mm})$ & Bar type & $\rho_{1}(\%)$ & $\rho_{2}(\%)$ \\
\hline R-F60-M6-A & 2250 & 1500 & 60 & $\mathrm{M} 6$ & 0.24 & 0.24 \\
R-F60-P6-A & 2250 & 1500 & 60 & $\mathrm{P} 6$ & 0.24 & 0.24 \\
S-F60-M6-A & 1500 & 1500 & 60 & $\mathrm{M} 6$ & 0.24 & 0.24 \\
R-F40-D6-B & 2250 & 1500 & 40 & $\mathrm{D} 6$ & 0.35 & 0.35 \\
R-F60-D6-C & 2250 & 1500 & 60 & $\mathrm{D} 6$ & 0.24 & 0.48 \\
R-F60-D6-A & 2250 & 1500 & 60 & $\mathrm{D} 6$ & 0.24 & 0.24 \\
S-F60-D6-A & 1500 & 1500 & 60 & $\mathrm{D} 6$ & 0.24 & 0.24 \\
S-F60-D6-D & 1500 & 1500 & 60 & $\mathrm{D} 6$ & 0.52 & 0.52 \\
S-F60-D8-D & 1500 & 1500 & 60 & $\mathrm{D} 8$ & 0.52 & 0.52 \\
S-F60-P6-A & 1500 & 1500 & 60 & P6 & 0.24 & 0.24 \\
R-F60-M6-A & 2250 & 1500 & 60 & $\mathrm{M} 6$ & 0.24 & 0.24 \\
R-F40-M6-B & 2250 & 1500 & 40 & $\mathrm{M} 6$ & 0.35 & 0.35 \\
R-F60-D8-A & 2250 & 1500 & 60 & D8 & 0.28 & 0.28 \\
R-F60-D8-C & 2250 & 1500 & 60 & D8 & 0.28 & 0.56 \\
\hline
\end{tabular}


(a)

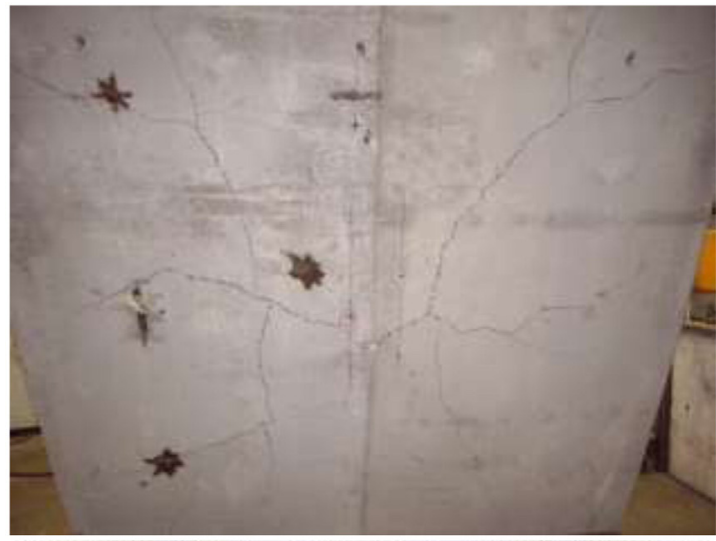

(b)

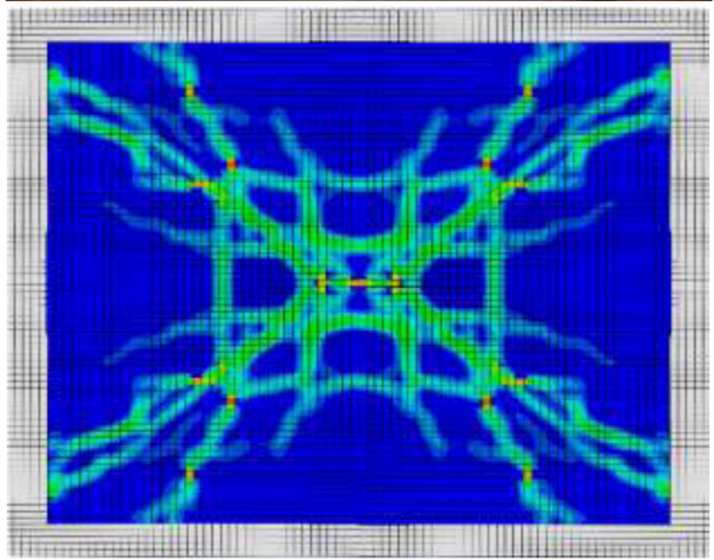

Fig. 18. Crack pattern for S-F60-M6-A (a) from the experimental programme [2] and (b) predicted by ABAQUS.

crack model that requires the specification of the relationship of tensile stress to cracking strain. In order to adapt the CEB-FIP stress-crack opening diagram to the ABAQUS input requirements, the CEB-FIP crack opening values were divided by a crack band width $\left(w_{c}\right)$, ranging from $2 d_{a}$ to $4 d_{a}$ where $d_{a}$ is the maximum aggregate size $[19,20]$.

Fig. 21 shows the resulting stress-strain relationships using both the Wang and Hsu and the adapted CEB-FIP approaches for reduction factors (RF) of $0.4,0.7$ and 1.0 and crack band widths of 20,50 , and $100 \mathrm{~mm}$, respectively. In order to evaluate the effect of the tensile material representation of concrete, the response of slab strip UR1 from Table 1 is modelled using both the Wang and Hsu and the CEB-FIP methods; the results are presented in Fig. 22. It is noteworthy that the

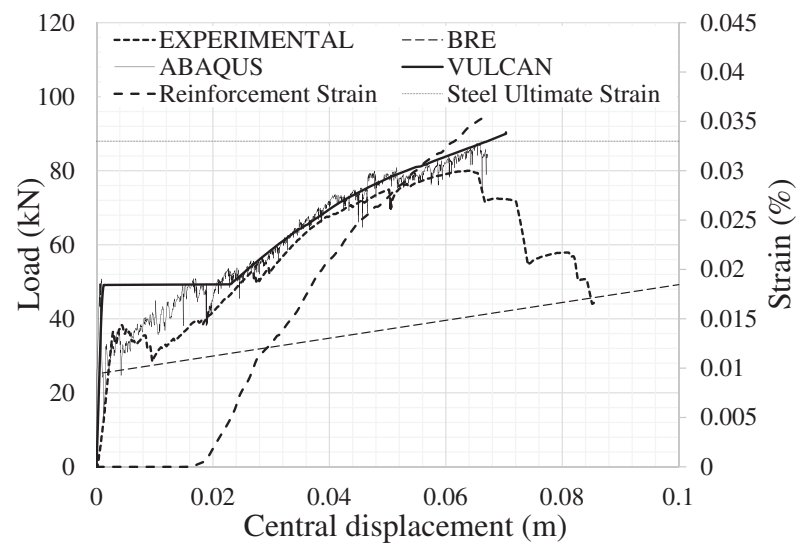

Fig. 19. Load-displacement response of S-F60-M6-A (primary axis) and strain induced in the reinforcement along the formed yield line for the corresponding vertical displacement (secondary axis).

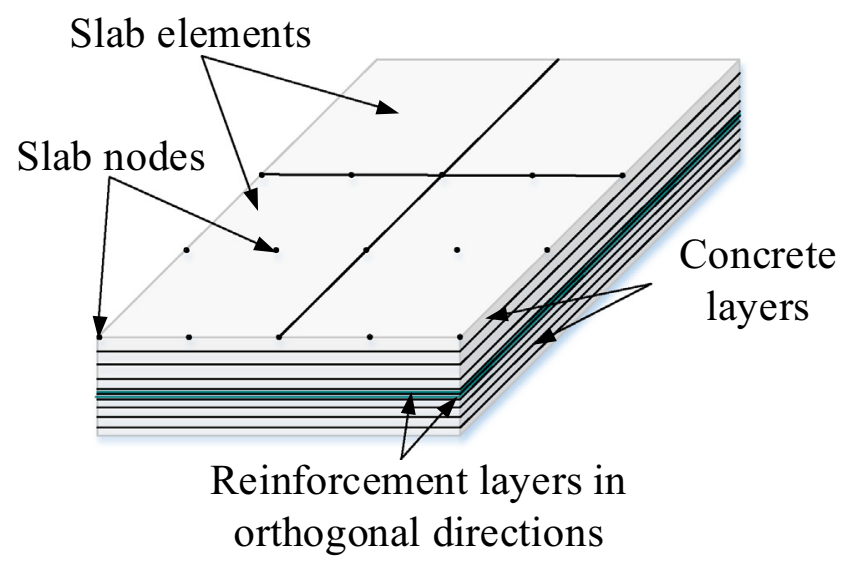

Fig. 20. 9-noded quadrilateral plate element employed for analysis in VULCAN.

area beneath the Wang and Hsu tensile stress-strain curves when $\mathrm{RF}=1,0.7$ or 0.4 is very similar to the areas under the adapted CEBFIP curves with crack widths of 20,50 or $100 \mathrm{~mm}$, respectively. This corresponds to a similar amount of energy released during the fracture process therefore the overall response is expected to be similar as well, as evident in Fig. 22(a) and Fig. 22(b).

As illustrated in these figures, using either of the two modelling approaches results in to a reasonable approximation of the experimental response. Using a reduction factor of 0.7 results in the best approximation of the experimental response for this test, which contained M6 reinforcement, as shown in Fig. 22(a). After the formation of the first crack, a second crack develops when central deflection reaches approximately $5 \mathrm{~mm}$, reducing the capacity of the element considerably. When this second crack is formed (Fig. 16(b)), the capacity of the element depends mainly on the properties of the reinforcing steel to up to the point of failure (i.e. the tensile strength of concrete has been exceedingly reduced at this level of deflection). This is found to be valid for all cases of lightly reinforced elements tested with reinforcement to concrete ratio $(\rho)$ between 0.24 and 0.52 .

\subsubsection{Effect of bond strength on the numerical response}

It has been shown that the bond strength between the steel reinforcement and surrounding concrete is of great importance in the ultimate behaviour of lightly reinforced concrete members at large displacements [14]. The amount of bond between the steel reinforcement and surrounding concrete affects the development of cracks as well as the distribution and concentration of strain in the reinforcement. Hence, it is extremely influential to the ultimate behaviour particularly.

As described earlier, the CDP model in ABAQUS does not explicitly model the interaction between reinforcing steel and concrete and

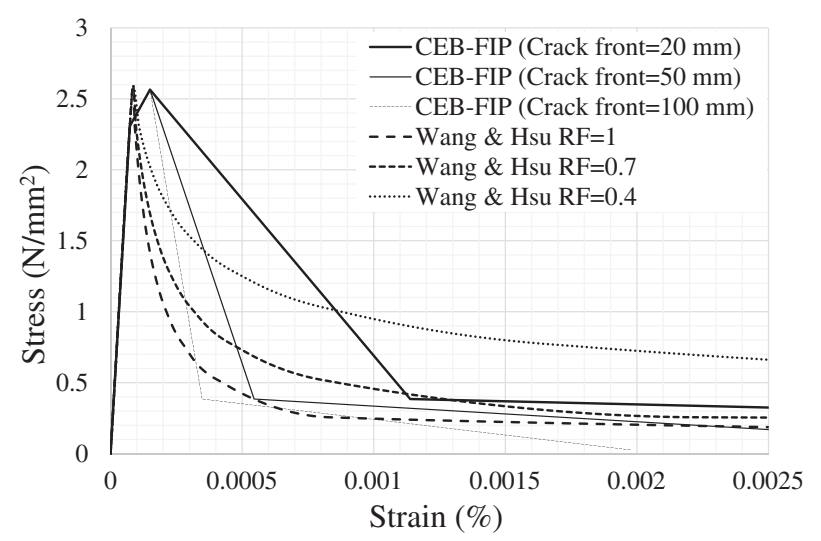

Fig. 21. Comparison of the tensile stress-strain relationships. 
(a)

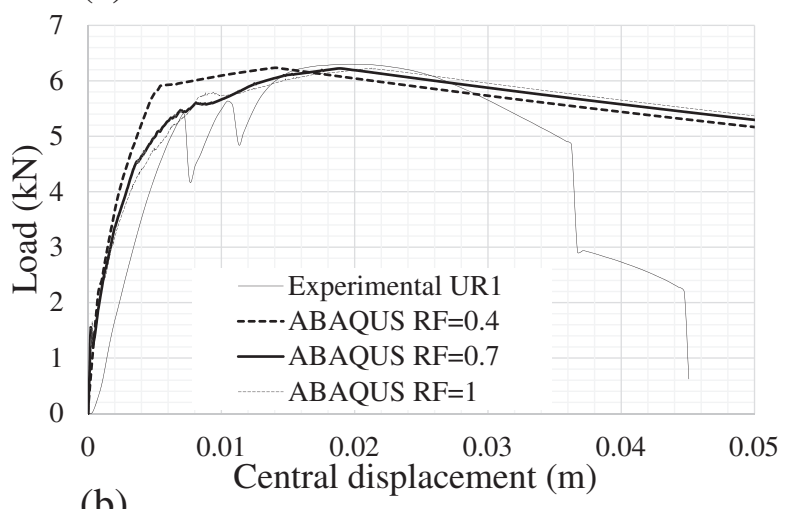

(b)

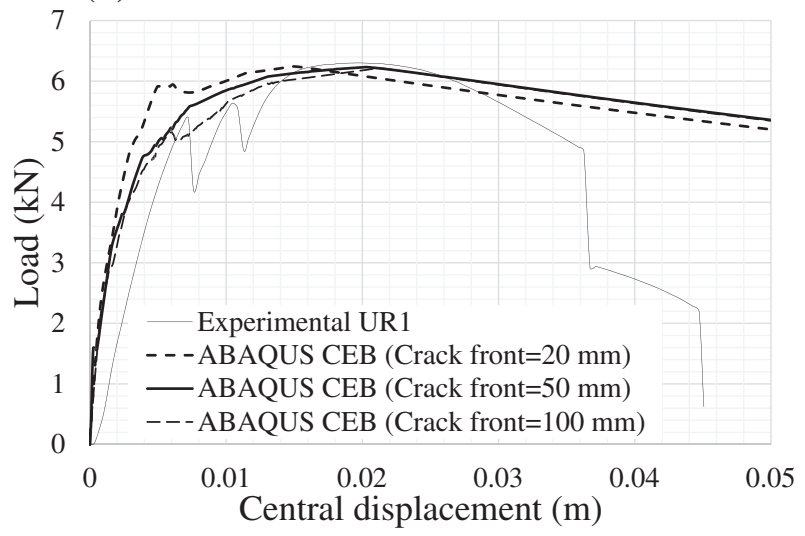

Fig. 22. Model response using the (a) Wang and Hsu, and (b) adapted CEB-FIP tensile properties.

actually depicts the bond inherently through the tension stiffening parameter. Once cracking occurs in the concrete, a significant increase in stress in the reinforcement at the location of the crack occurs, as a result of the embedment technique. In order to further investigate this stress and strain distribution in the steel reinforcement, specimen UR14 is employed herein for detailed analysis. This specimen is selected because it is one of three from the aforementioned one-way spanning slab strip test programme (i.e. UR14, UR15 and UR16) that contained reinforcing bars which were instrumented internally with strain gauges along the length. All three of these specimens were reinforced with $8 \mathrm{~mm}$ bars in an identical arrangement, although the overall depth varied between 60 and $120 \mathrm{~mm}$ to give different reinforcement ratios. In the experimental programme, the central bar in each of these tests was instrumented with strain gauges along the length within a specially-milled duct, whilst the remaining bars were solid. This enabled a direct assessment of the strain and bond distribution along the member length [14]. The analysis which follows of UR14 is similar to that which was observed for UR15 and UR16.

The distribution of strain along the central reinforcing bar for UR14 is presented in Fig. 23(a) for central deflections at $10 \mathrm{~mm}$ intervals between 10 and $30 \mathrm{~mm}$ and Fig. 23(b) for deflections of 40, 50, 60 and $68 \mathrm{~mm}$, respectively. Also presented in the figures are the ABAQUS predictions for the same strain distributions. It is noteworthy that in the experimental programme, the strain gauges were only capable of reading strains up to around $2.5 \%$, after which the measurement became unreliable. Fig. 23(a) clearly shows that the strain concentrates in the central part of the strip once cracking occurs, as expected.

The FEM data are generally in good agreement with the experimental results. There is a notable absence of local peaks at either end of the central-crack region in the FEM data, compared with the experiment. These locations correspond to secondary cracks which occurred in the test, and are depicted by the FEM (see Fig. 16(b), (c) and (d)) but, the
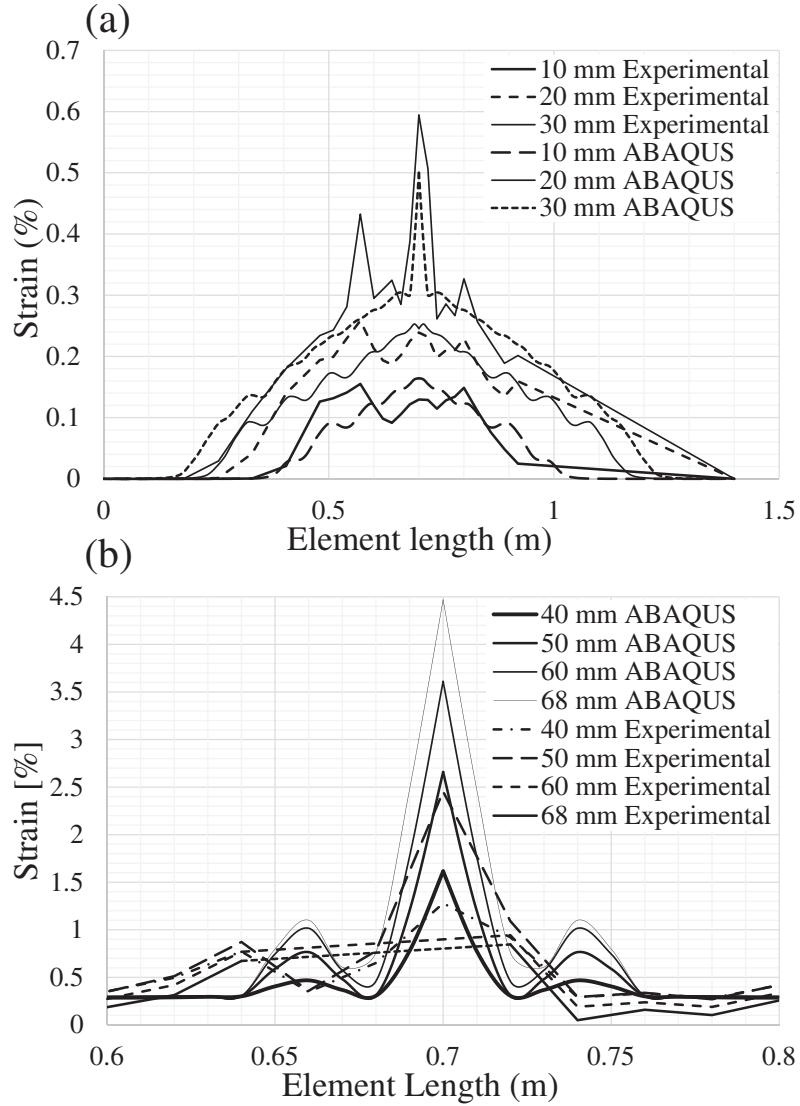

Fig. 23. (a) Strain gauge and ABAQUS data at $10-30 \mathrm{~mm}$ of deflection, and (b) at $40 \mathrm{~mm}$ to failure.

model does not fully capture the levels of stress transferred from the concrete to the embedded steel. This is most likely due to the tension stiffening property discussed earlier. At higher levels of deflection, as shown in Fig. 23(a), the strain in the reinforcement is well represented by the FEM both at the primary and the secondary cracks. As the deflection increases towards the recorded failure value of $68 \mathrm{~mm}$, the strain gauges fail to provide data for comparison, as explained earlier. However, the FEM predicts that the strain in the steel is around $4.4 \%$ which is comparable to the actual failure strain of the reinforcing bars of $4.1 \%$. The FEM predicts that failure occurs by reinforcement fracture at a deflection of $66 \mathrm{~mm}$ which is satisfactory compared with the actual failure displacement of $68 \mathrm{~mm}$. It is noteworthy that in terms of the failure prediction, the FEM is capable of predicting when reinforcement fracture will occur, once the concrete model has been reliably calibrated. The calibration process in this study, only considers instantaneous stressrelated strain and thermal strain in the elevated temperature. Creep strains, although significant when the loading period I relatively long, are ignored because the assumption is made that the loading period in this case is not long enough for creep to be significant.

\section{Elevated temperature response}

In this section, the ABAQUS FEM developed previously for ambient temperature conditions is extended to consider the effects of elevated temperature.

\subsection{Elevated temperature numerical model}

The sequentially coupled thermal-stress analysis procedure in ABAQUS/Explicit was used to represent the slabs behaviour at elevated temperature. This approach has been used by other researchers [24] and 
was employed because the stress/displacement solution is dependent on a temperature field without any inverse dependency. The sequentially coupled thermal-stress analysis was performed by first performing a heat transfer analysis to obtain the temperature distribution through the cross-section of the slab and then importing these values into the stress analysis.

ABAQUS allows different mesh discretisation to be used between the two stages of the analysis and so a finer mesh was employed in the heat transfer stage section, particularly through the depth. This was to ensure that the nodes at the reinforcement level in the stress analysis are matched by the nodes at the same locations in the heat transfer analysis and the temperature of the embedded reinforcement depicted accurately. As in the ambient temperature model, the concrete was modelled using the concrete damaged plasticity (CDP) model whilst the reinforcement was modelled as an elastic material with plastic hardening (see Section 2.4).

\subsection{Results from the elevated temperature numerical model}

The same slab previously modelled at ambient temperature (i.e. SF60-M6-A) is again presented in this section to illustrate the results at elevated temperature. A uniformly distributed load of $15 \mathrm{kN} / \mathrm{m}^{2}$ was applied to the concrete surface; this load level results in an elastic response at ambient temperature (Fig. 19). The slab was then subjected to the standard ISO 834 fire curve [25], as included in EN 1991-1-2 [26], for $90 \mathrm{~min}$. The temperature values for the top, bottom and reinforcement layers are presented in Fig. 24.

Fig. 25 presents the crack pattern simulated by the ABAQUS model which is observed to be very similar to that presented in Fig. 18 for the same slab at ambient temperature and also to the pattern predicted by yield line theory. This indicates that a similar failure mechanism is likely to occur both at ambient and elevated temperature.

\subsection{Validation of the elevated temperature numerical model}

In order to verify the results obtained from the ABAQUS numerical model, a comparison of the behaviour is made with the FE code VULCAN which has been extensively validated for similar elevatedtemperature applications (e.g. [25]). VULCAN considers the nonlinear elevated-temperature material behaviour. The model created in VULCAN has similar material and loading properties to those in the ABAQUS model. The slab elements are meshed so that the layers are compatible with the VULCAN layered quadrilateral plate element. The heat transfer component of the analysis is performed in ABAQUS because VULCAN does not readily have this capability and then the temperature values in the various layers are imported into the VULCAN model.

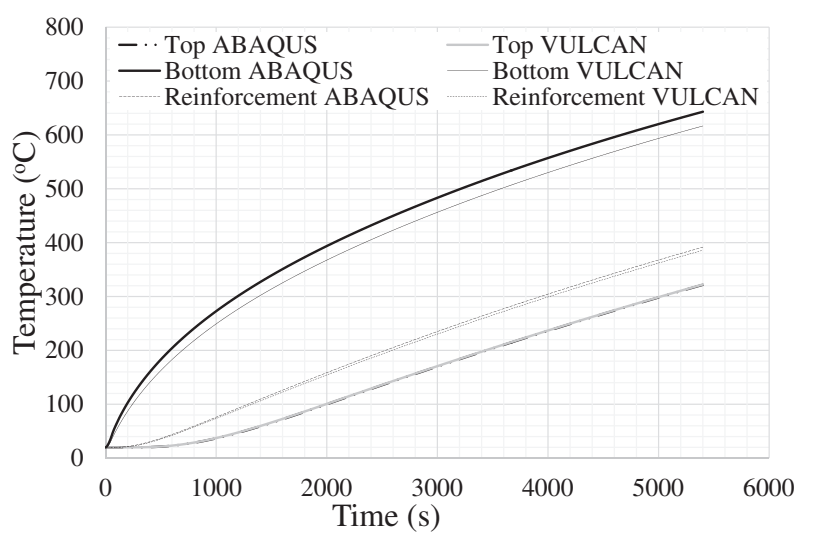

Fig. 24. Temperatures at key layers for ABAQUS and VULCAN stress analysis.

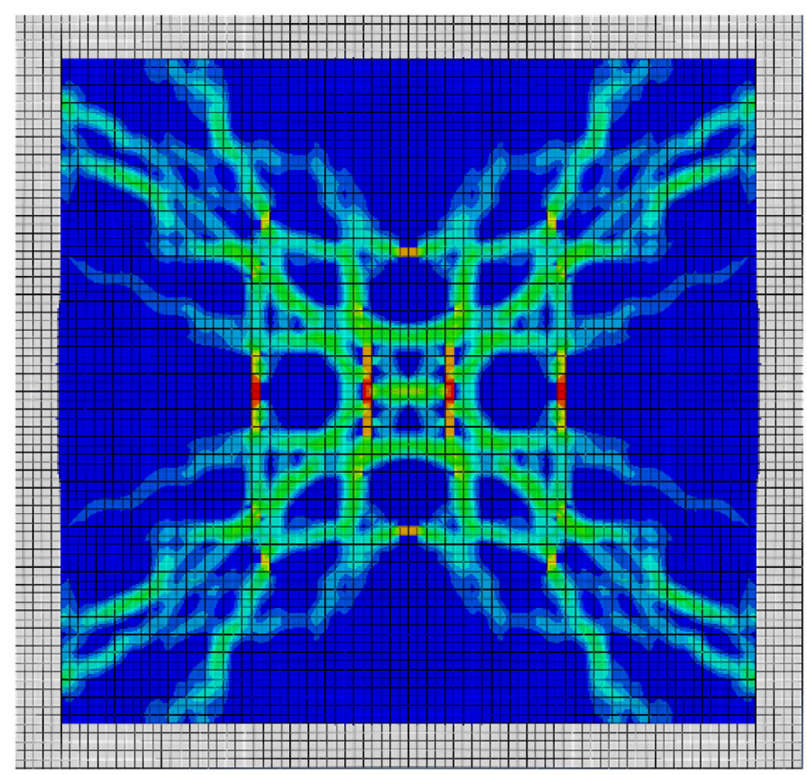

Fig. 25. Crack pattern for S-F60-M6-A after the elevated temperature analysis.

As before, during the heat transfer analysis, the slab is subjected to the standard ISO 834 fire curve for $90 \mathrm{~min}$. It is assumed that there is a linear distribution of temperature along each layer of the VULCAN model and therefore the nodal temperatures from the ABAQUS heat transfer analysis are used to calculate the average temperature in each layer. There is a minor difference between the ABAQUS nodal temperatures and the VULCAN average layer temperatures although this reduces towards the unheated site of the slab. Of particular interest is the temperature on the reinforcement layer where the difference is insignificant.

The graph in Fig. 26 presents the results of the ABAQUS and VULCAN models in solid and dashed lines, respectively. It is observed the two approaches are in reasonable agreement although discrepancies do occur, particularly at high temperatures; this is most likely to be due to differences in the development of cracks.

The BRE simplified design method has also been used to analyse this slab at elevated temperatures and the results compared to those from the ABAQUS and VULCAN FE models; these predictions are also presented in Fig. 26. This analytical method estimates the load-carrying capacity of a lightly reinforced concrete slab as a function of the vertical displacement based on the in-plane stresses (membrane action) in the slab. By incorporating the thermal effects on the material properties in the equations the temperature-displacement response of the slab can

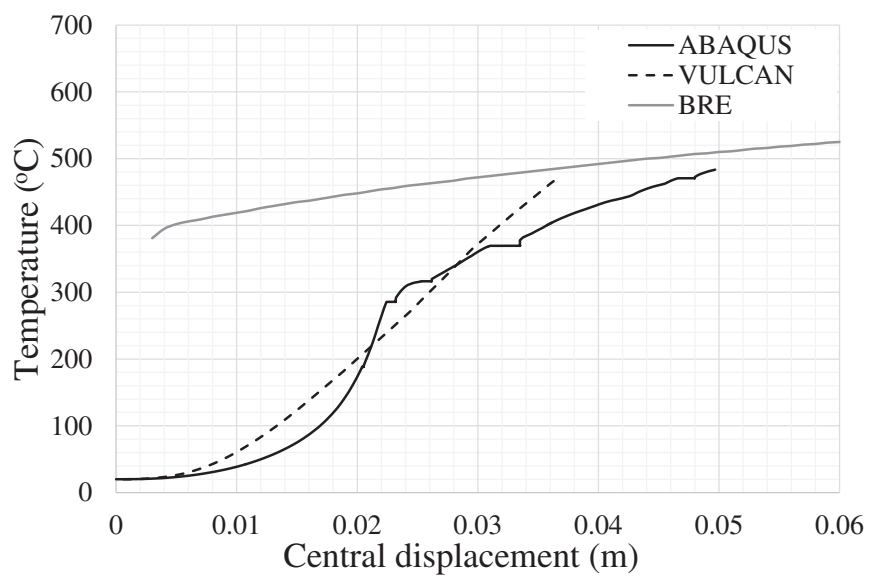

Fig. 26. Temperature-displacement response of S-F60-M6-A. 
be extracted. The exact procedure is described in detail in [5] but the results demonstrate that the BRE simplified design method is in good agreement at large deflection levels with the response predicted by the two models, contrary to the estimated response at ambient temperatures. Additionally it is important to note that the estimated response of the model using this method will vary significantly compared to numerical and experimental results at small deflections before the response stabilises as the deflection increases. This can be clearly seen in Fig. 26 where there is a significant difference in the temperature needed to develop the equivalent initial deflection between the BRE and the numerical models in VULCAN and ABAQUS.

\section{Conclusions}

This paper has presented numerical studies into the behaviour and ultimate response of one-way spanning strip and two-way isolated, lightly reinforced slab elements such as those encountered in steelframed composite structures. Particular attention has been given in creating a reliable FEM able to predict with good accuracy failure either by reinforcement rupture or concrete crushing. Towards this end, the results of an experimental test series consisting of sixteen ambient tests on one-way and fourteen tests of two-way isolated elements were utilised to calibrate and validate the model. It was shown that the numerical model which has been developed in the ABAQUS software can realistically represent the behaviour at large deflections. Importantly, this model accounts for the relationship with the steel reinforcement and surrounding concrete.

This, in turn, led to the validation of the model using the previouslyvalidated VULCAN software, and compared the results to the BRE simplified design method for both ambient and elevated temperature. Important parameters that influence the outcome of the FEM have been identified and discussed where appropriate. The work described in this paper is the first step in a larger research programme and the future targets include:

- Validating the model against experimental data on isolated slab elements at elevated temperature;

- Expanding the model to include the influence of neighbouring compartments on the overall behaviour in fire;

- Using the validated model to develop an understanding of the most salient parameters such as boundary conditions, continuity, bond strength and various other material and geometric properties under ambient and elevated temperatures on the overall response; and

- Proposing performance-based expressions which can be used in design for the ultimate response of floor slabs under fire conditions

The results of this investigation will offer detailed insights into the key factors that govern the ultimate behaviour of buildings with composite floor systems under extreme loading conditions, and provide the essential background to enable the development of more performance-based design expressions.

\section{References}

[1] Bailey CG. Membrane action of slab/beam composite floor systems in fire. Eng Struct 2004;26(12):1691-703.

[2] Cashell KA, Elghazouli AY, Izzuddin BA. Failure assessment of lightly reinforced floor slabs. I: experimental investigation. J Struct Eng 2011;137(9):977-88.

[3] Cashell KA, Elghazouli AY, Izzuddin BA. Failure assessment of lightly reinforced floor slabs. II: analytical studies. J Struct Eng 2011;137(9):989-1001.

[4] Martin D, Moore D. The behaviour of multi-storey steel framed buildings in fire. UK: British Steel Plc; 1999.

[5] Bailey CG, Toh W. Behaviour of concrete floor slabs at ambient and elevated temperatures. Fire Saf J 2007;42(6):425-36.

[6] Elghazouli AY, Izzuddin BA. Realistic modelling of composite and reinforced concrete floor slabs under extreme loading. II: verification and application. J Struct Eng, ASCE 2004;130(12):1985-96.

[7] Huang Z, Burgess IW, Plank RJ, Bailey C. Comparison of BRE simple design method for composite floor slabs in fire with non-linear FE modelling. Fire Mater 2004; 28(2-4):127-38.

[8] Bailey CG, Moore D. The structural behaviour of steel frames with composite floor slabs subject to fire. Pt. 2: design. J Struct Eng 2000;78(11):19-27.

[9] Newman GM, Robinson JT, Bailey CG. A new approach to multi-storey steel-framed buildings P288. Ascot, UK: The Steel Construction Institute; 2000.

[10] Burgess IW, Huang SS, Staikova S. A re-examination of the mechanics on tensile membrane action in composite floor slabs in fire. 8th international conference on structures in fire, Shanghai, China; 2014

[11] ABAQUS. ABAQUS user's manual version 6.13-2. Rhode Island, USA: Hibbitt, Karlsson \& Sorensen, Inc.; 2013.

[12] Lim L, Buchanan A, Moss P, Franssen JM. Numerical modelling of two-way reinforced concrete slabs in fire. Eng Struct 2004;26(8):1081-91.

[13] Belarbi AB, Zhang LX, Hsu TT. Constitutive laws of reinforced concrete membrane elementsEleventh World Conference of Earthquake Engineering, Acapulco, Mexico; 1996.

[14] Cashell KA, Elghazouli AY, Izzuddin BA. Experimental and analytical assessment of ductility in lightly reinforced concrete members. Eng Struct 2010;32(9):2729-43.

[15] CEB-FIP. Model code for concrete structures MC90. London: Thomas Telford; 1991

[16] Kmiecik P, Kamiński M. Modelling of reinforced concrete structures and composite structures with concrete strength degradation taken into consideration. Arch Civ Mech Eng 2011;11(3):623-36.

[17] EN 1992-1-2. Eurocode 2: design of concrete structures-part 1-2: general rulesstructural fire design. UK: British Standards Institution; 2004.

[18] Selby RG, Vecchio FJ. A constitutive model for analysis of reinforced concrete solids. Can J Civ Eng 1997;24(3):460-70.

[19] Bažant ZP, Oh BH. Crack band theory for fracture of concrete. Mater Struct 1983;16: 155-77.

[20] Bažant ZP. Fracture in concrete and reinforced concrete. In: Bažant ZP, John Wiley \& Sons Ltd., editors. Mechanics of Geomaterials; 1985.

[21] Wang T, Hsu TT. Nonlinear finite element analysis of concrete structures using new constitutive models. Comput Struct 2001;79(32):2781-91.

[22] EN 1992-1-1. Eurocode 2: design of concrete structures: part 1-1: general rules and rules for buildings. UK: British Standards Institution; 2004.

[23] Huang Z, Burgess IW, Plank RJ. Modeling membrane action of concrete slabs in composite buildings in fire. I: theoretical development. J Struct Eng 2003;129(8): 1093-102.

[24] Nguyen TT, Tan KH, Burgess IW. Behaviour of composite slab-beam systems at elevated temperatures: experimental and numerical investigation. Eng Struct 2015; 82:199-213.

[25] ISO 834-11. Fire resistance tests - elements of building construction part 11: specific requirements for the assessment of fire protection to structural steel elements. International Organization for Standardization; 2014.

[26] EN 1991-1-2. Eurocode 1: actions on structures-part 1-2: general actions-actions on structures exposed to fire. UK: British Standards Institution; 2002 